LAW, ETHICS, AND MEDICINE

\title{
Human organs, scarcities, and sale: morality revisited
}

\author{
R R Kishore
}

J Med Ethics 2005;31:362-365. doi: 10.1136/jme.2004.009621

Despite stringent and fine tuned laws most jurisdictions are not able to curb organ trafficking. Nor are they able to provide organs to the needy. There are reports of the kidnapping and murder of children and adults to "harvest" their organs. Millions of people are suffering, not because the organs are not available but because "morality" does not allow them to have access to the organs. Arguments against organ sale are grounded in two broad considerations: (1) sale is contrary to human dignity, and (2) sale violates equity. Both these objections are examined in this article and it is concluded that they reflect a state of moral paternalism rather than pragmatism. It is argued that a live human body constitutes a vital source of supply of organs and tissues and that the possibilities of its optimum utilisation should be explored. Commercialisation should be curbed not by depriving a needy person of his genuine requirements but by making the enforcement agencies efficient.

Correspondence to: R R Kishore, President, Indian Society for Health Laws and Ethics, D-II/145 Kidwai Nagar (West) New Delhi-110023, India; rrkishore@vsnl.com

Received 13 July 2004 Accepted for publication 17 July 2004 no database and reliable studies are yet to be conducted but in view of the country's large population of nearly 1.2 billion and the rising incidence of end stage renal disease (ESRD), the requirement for kidney transplantation alone is expected to be around 80000 per year but not even 5000 transplants are conducted. Strategies such as liberalisation of the concept of brain stem death; introduction of presumed consent; routine harvesting; required request; mandated choice; raising the donor's upper age limit; relaxation of restrictions imposed on donations among family members; and allowing altruistic donations from strangers have not resolved the problem. Organ scarcity continues to prevail, leading to inequitable therapeutic dispensation; escalating costs; trade; crime; and premature death. In India there are periodic reports of organ trafficking involving clinicians, managers of clinical centres, middle men, and even state officials; several cases are at present under active investigation or at trial. The "worldwide shortage of kidneys from cadavers has resulted in illicit organ sales and even kidnapping and murder of children and adults to 'harvest' their organs". ${ }^{4}$ Millions of people are suffering, not because the organs are not available, but because "morality" does not allow them to have access to the organs.

The question is what is good and what is bad. How are we to measure the moral content of a particular act? Morality is always contextual. It depends on how and in what context we interpret values. The famous Roman physician Galen-for example, did most of his anatomy research on pigs and dogs as it was regarded as immoral to dissect humans at that time, ${ }^{5}$ but, subsequently, dissection of human cadavers during medical education became a routine practice. The issue of biotechnological achievements and their social assimilation contemplates a much deeper dialogue than is being conducted in contemporary ethical discussions. This paper is an attempt in that direction.

\section{ESSENTIAL QUESTIONS AND VALUES}

The basic ethical principle involved in organ transplantation is whether a person has a right to enjoy life on the basis of organs belonging to others. Once we choose to answer this question in the affirmative we concede that we are prepared to inflict harm on others in order to improve our health or to prolong our life. Thus we sacrifice the long cherished principle of nonmaleficence in medicine. Whether the organs come through donation, gift, or sale is a matter

†Eurotransplant is an organisation of the European Union founded to promote and monitor the activity of organ transplantation in certain European jurisdictions. 
of individual choice and circumstances. Even if a person gives his organ willingly and without any thought as to recompense he suffers harm to his body.

It is a fact that in every gift or donation some kind of expectation is involved, though it may not be a material consideration. In the case of live organ donors the organ is donated to a particular person who, in fact, may not be the neediest or the most deserving bearing in mind the seriousness of illness; period of waiting; age; family circumstances; capability to afford post-transplantation therapy, and other criteria. This means that the act of donation is tainted with considerations of personal relationship, choice, and preference. In other words the donation is not a candid act of altruism or human solidarity, but rather is motivated by the desire to save the life of a near and dear one, which may, at times, be to secure one's own comfort and future. Such urges and motives also constitute considerations other than altruism since they are aimed at pleasure and fulfilment. Even a donation made to a stranger is not without considerations of possible benefit. Such cases may be motivated by the desire to discharge a religious duty; to correct a wrong done in the past; to gain mental or moral satisfaction; or to be seen as a good Samaritan.

Once the practice of organ donation by the genetically related and also by strangers, based on altruism, has been accepted as ethically sound the following components of organ removal stand morally vindicated:

(a) A person's expectation to enjoy life with the help of organs belonging to others is valid, and

(b) the breach of a donor's bodily integrity and the consequent harms are permissible.

Judged on these values a person's act of severing his/her organ in order to liberate a fellow being from a terminal illness or to save his/her life cannot be dubbed as immoral simply because the act is accompanied by a reasonable material consideration. "When a person sells an organ he or she acts both selfishly, in advantaging him or herself, and altruistically, in contributing to a public good. ${ }^{\prime \prime 6}$ The presence of considerations is not a sufficient reason to transform a simple act into a sin. Otherwise, selling water to the thirsty would be an equally big sin in fact rather a bigger one.

To equate an organ vendor with a criminal committing a heinous crime, as is reflected in the legislative strategies of many jurisdictions, is misconceived. Several jurisdictions provide stringent punishment for organ sale in utter disregard of the circumstances that compel a person to sell her/his organ. The punishment ranges from 3 months' imprisonment and/or a fine, as in the $\mathrm{UK}^{7}$ to 8 years' imprisonment and/or a fine, as in Venezuela. ${ }^{8}$ In India the punishment may extend up to 7 years' imprisonment and/or a fine up to Rs 20 000.' Such punishments are prescribed only for serious offences and it is thus clear that organ sale is treated as a serious offence, worldwide. Such an approach does not seem to be correct. A person who sells his organ does so because he knows that his organ is going to save the life of a fellow human being and as such he is convinced that he is not doing anything immoral or inhuman. Had he known that his act would lead to loss of life, property, or inflict any other kind of injury on the buyer he would not have sold his organ. A criminal, has no such moral conviction or justification and commits the act solely for his personal gain, without caring for the loss or injury suffered by the victim. As such, it seems that the legislative strategies in the area of organ transplantation have not been realistic.

\section{ARGUMENTS AGAINST FINANCIAL INCENTIVE AND SALE}

Policies on organ transplantation reflect a unique social paternalism. Objections against the sale of organs such as;
"(1) the dilution of altruism in society; (2) the risk that the quality of donated organs would decrease; (3) doubts about the voluntariness of those who accept financial incentives for donation, and (4) the treatment of human beings and their parts as commodities"10 do not reflect an objective approach. Recent critics of markets in organs give two main reasons to support their opposition: (1) "the integrity of the human body should never be subject to trade", and (2) a system is unethical "when it penalises the weakest people and exacerbates discrimination based on census" and generates "the risk of exploitation of vulnerable donors". ${ }^{11}$ Some are more sceptical and feel that the "poor of the developing world could become a vast reservoir" of organs for the developed world ${ }^{12}$ and that the poor in a "starved country" can never be "fully informed and autonomous donors". ${ }^{13}$ Others feel that it amounts to "exploitation of potential donors". ${ }^{14}$

Arguments against organ sale are thus grounded in two broad considerations: (1) sale is contrary to human dignity, and (2) sale violates equity. Let me examine these one by one.

\section{IS SALE CONTRARY TO HUMAN DIGNITY?}

In contemporary ethical deliberations human dignity has become a very handy tool to measure the ethical content of biotechnological applications, at times, without appreciating its true nature, ambit, and implications. It is not within the scope of this paper to deal with human dignity in its entirety but it may, however, be worthwhile to know what it means in essence. Essentially speaking, human dignity is an expression of the human content of Homo sapiens. It is an expression of the properties or virtues due to which a human creature is known as a human being. These are the characteristic or attributes that are unique to the human race and not possessed by any other living form. What are these virtues? These virtues, known in Vedic thought as dharma, are ten in number-namely, love, trust, righteousness, compassion, tolerance, fairness, forgiveness, beneficence, sacrifice, and concern for the weak. With these human virtues in mind, any act done to save the life of a human being or to liberate him from suffering cannot be construed as contrary to human dignity. The presence of a consideration does not alter the basic content of an act such as an organ sale, which is grounded in the need to save at least two human lives, one from terminal illness (the recipient), the other from hunger (the donor). The concept of human dignity does not demand that people should be forced to die a premature death where an illness can be cured nor that people who donate organs should die of hunger and their families be left to starve. Rather, it will be contrary to human dignity to promote such an act. The matter of payment is a logistical dimension, not the substantial aspect of the transaction. Retrieval of organs from the dead by presuming consent on their behalf or the act of declaring a person brain stem dead in order to remove organs from his body are devices designed solely to augment organ supply but they are not regarded as contrary to human dignity. Prohibition on sale of organs makes matters worse by restricting transparency, fairness, and choice and by generating arbitrariness, fear, and bribes. Vendor and buyer are rendered vulnerable because of the introduction of an unwarranted legal component that brings in many players such as police, lawyers, adjudicators, and social activists, each with their own philosophy and interest, thereby transforming a simple activity into a highly complex exercise.

The argument that there cannot be genuine and free consent to the sale of organs is not well founded. In fact such an argument is an antithesis of the concept of autonomy. The decision to sell an organ, taken by a person after considering all circumstances, consequences, options, and possibilities cannot be disregarded by others on the ground that it has 
been taken under undue influence or inducement. The individual is the best judge as to what is best for him in a given situation and so long as his decision does not affect others he cannot be stopped from acting upon his decisions. If the vendor is not able to give free and informed consent because of the pressures of poverty and the lure of money, the buyer is also not able to give such consent because of the pressures of illness and the urgent need to save his life. The donor too is unable to give free and informed consent because of the fear of losing a near relative and possibly the consequent loss of support and security. Thus none of the parties involved is capable of giving free and informed consent because of the compelling circumstances in which they find themselves. This means that the whole exercise of organ transplantation is inconsistent with the principle of free and informed consent and therefore is unethical. Why then should only the vendor be declared an offender?

Arguments linking a person's autonomy to bodily "integrity" or "fullness" and on this basis declaring organ sale as "misuse" of "our autonomy"15 appear misconceived because if that is the case "integrity" or "fullness" is also breached in the case of donation, which is not considered to be unethical.

In order to justify the failure to provide organs to the needy, various considerations, such as old age, associated diseases, poor prognosis, and irresponsible behaviour, are brought up in order to exclude a number of potential organ recipients, knowing fully that in such cases "the alternative to transplantation is death". ${ }^{16}$ Organ scarcity has polluted the moral concepts involved in transplantation and some feel "alcoholics should be given lower priority for a liver because of their moral vice of heavy drinking" ${ }^{\prime 17}$ and "lung transplantations" should not be offered "to people who smoke or have other substance abuse in the last six months". ${ }^{18}$ Despite the fact that brain stem death and human death are not the same, the definition of death has been liberalised in order to give an "incessant push to expand the pool of potential organ donors". ${ }^{19}$ Thus, the prohibition on sale is not without heavy costs, which include untimely death, poor quality of life, higher disease burden, moral bias, and premature certification of death. Is this consistent with human dignity?

It is significant that the concept of human dignity is being selectively applied in the case of certain tissues only. Blood, bone marrow, sperm, and eggs are being openly sold and a woman can "command \$50,000 for her donated eggs" (Kahn, ${ }^{14}$ p l) but their sale, it seems, does not attract notion of human dignity.

\section{IS SALE VIOLATIVE OF EQUITY?}

1. The apprehension that organs will become costly, going beyond the reach of the common man is unfounded. Costs can always be controlled by the state through the use of regulatory mechanisms, as is done in the case of other goods and services. Furthermore, socioeconomic inequalities are present in all walks of life, not only in organ transplantation. The whole healthcare system is subject to market forces. Many drugs, many pieces of equipment, appliances, procedures, and services are prohibitively costly and are not accessible to all those who need them. In many jurisdictions, they have to be imported from the developed and industrialised countries, which, at times, monopolise their trade. Despite strong objections from the public who desire health care to be available as a welfare measure there has been an increasing commercialisation of healthcare services. Organ transplantation is also a part of this overall milieu.

2. The purchase of organs is likely to have only a marginal impact on the cost of transplantation procedures. In many countries, including India, where there have been reports of organ trafficking, kidneys are sold for as little as 400-500
US\$, while reports on the total cost of a kidney transplantation vary widely, ranging from 1000 US $\${ }^{20}$ to 8000 US $\$ .{ }^{21}$ Dr Raymond Crockett, debarred from practising in Britain in 1990, for professional misconduct, arranged for kidneys to be bought from Turkish people for 2500-3500 pounds sterling, but charged each patient 66000 pounds for the transplantation. ${ }^{22}$ This shows that the cost of organs is just a fraction of the total transplantation cost, which, in fact, is much higher if the post-transplantation immunosuppressive therapy and the other follow up care is taken in to account. The apprehension in some quarters that organ sales will create a market mechanism that will greatly increase transplantation costs is therefore misconceived. Rather, the free availability of organs will reduce the costs of transplantation by curbing the expenses incurred in clandestine operations and the middle men who are invariably associated with the organ trade, as has been made clear by the recent exposures in London ${ }^{23}$ and the Punjab. ${ }^{24}$ Organ transplantation is a costly medical intervention, mainly because of the high fees of the surgeons and others involved in the process. Organ sale is unlikely, therefore, to increase the transplantation costs substantially. Moreover, if organ sale is legitimised the cost can always be regulated by the state, as is being done in the case of other commodities. A better option to reduce transplantation costs is to regulate surgeons' fees, nursing home charges, and the price of equipment, appliances, and drugs.

3. With regard to the concern that once organ sale is legitimised organs will mainly be sold by "those who cannot afford to keep their organs", ${ }^{25}$ the matter requires deeper examination. The evidence thus far shows that in almost all cases, organs have been sold by persons in a state of abject poverty. In one case, in India, when I asked an organ seller why he had sold his kidney his reply was devastating: "I had nothing else to sell!" People surrounded by such brutal poverty and social deprivation do not have many options. Even when their organs are intact their lot is miserable because they suffer from hunger, diseases, and scorn. Society has so far done nothing to alleviate their suffering. The selling of an organ may provide them with some additional means and prolong their existence. If the sale of organs amounts to exploitation of the poor it is no more than a continuum of long drawn out process of their exploitation, which has been watched by society for centuries. The poor have been selling all that they possess for centuries in order to continue their existence. If, finally, selling their organs is the only way to get the money they need to prolong their existence, even if only temporarily, how can society stop them from doing so when society itself is unwilling to provide them with adequate means to survive. Why this sudden concern for the poor? A society passive to their problems for ages has no authority to interfere with the arrangement evolved by them to safeguard their survival. If, however, society truly feels they should not sell their organs, then their genuine needs should be addressed so that they are not forced to sell their organs. What kind of morality is it which snatches from the poor the only asset offered to them by nature? The prohibition on the sale of organs has worsened the lot of the poor. Buyers quite often refuse to pay or do not pay the agreed price. The vendor cannot assert his claim because of the fear of being prosecuted. Thus the strategy that was evolved for protecting the poor has been causing just the opposite effect.

There is one more aspect to the above issue. If a person who is not poor and in whose case there is no possibility of being exploited chooses to sell his organ will he be allowed to do so? If not, this means that the reasons for prohibiting organ sale are grounded not in the concern for the poor, but in some other considerations. 
4. The argument that permitting organ sale is not an equitable proposition since it restricts availability of organs only to affluent sections of the population is misconceived. How can it be fair to deny health care to those who wish to buy it using their own money, earned by honest means, on the ground that it is not available to others because of their inability to pay? If that is fair, why have we chosen a system of pricing for health care when many cannot pay even for the basic necessities, such as food and drinking water? Ours is an essentially heterogeneous society and equity has to be defined in realistic and pragmatic terms.

5. Prohibition on organ sale generates inequity by exerting undue pressure on the near relative who may "feel compelled to overlook the risks of organ donation when their loved one stands to receive so great a benefit" ${ }^{26}$ This pressure amounts to coercion, which is as bad as that exerted by the poverty and as such "should equally rule out donation". ${ }^{27}$ The sale provides a wider choice, the vendor may be much healthier than the donor, and his or her organ may be much more compatible with the recipient. Furthermore, during "removal of a vital part like a kidney the donor is subjected to a major surgical intervention which is not without risk. The recipient who is already sick is also exposed to a major surgical procedure with possibilities of complications. This means that two members of the same family are placed in a vulnerable situation thereby affecting the fate of other members of the family also. In case of any complications or untoward outcome the said family may be the victim of serious adversities. As such it seems safer to accept donation from a member of a different family". ${ }^{28}$

6. There is also a concern that there may be transnational movement of organs. The affluent countries, with the power of their money, may drain organs from the poorer countries thereby making the populations of the poorer countries even more vulnerable. This again is a problem of regulation, which can always easily be handled by banning exports of human organs or by adopting other suitable strategies.

7. The purpose of allowing the sale of organs is not to improve the health status of the sellers or to award them "a long term economic benefit", as conceived by some. ${ }^{29}$ Such economic or health benefit does not occur in altruistic donations either, but they are permissible. The reasons for permitting the sale of organs are grounded in the concern to save the lives of terminally ill patients with the help of available medical knowledge and technology by curbing "a contrived shortage created by existing organ procurement policies". ${ }^{30}$ As regards to poverty and ill health, they are rooted in factors other than organ sale and need to be addressed accordingly.

\section{CONCLUSION}

Those who were earlier destined to die carry a hope to survive, provided the biotechnology is allowed to unfold itself. It may be worth appreciating that medicine is always need based-that is, it is an aid to overcome physical or mental disability or disease. It cannot be equated with justice, art, or spirituality. It is also worth remembering that the right to relief from pain and suffering is intrinsic-that is, it is non-divestible. Any social policy leading to infringement of such a valuable right has to be founded on equally vital considerations. Donor and recipient are the major stakeholders in policies relating to organ transplantation and as such any policy that does not take into account their perspectives and views is not valid. The sale of organs is essentially rooted in the urge to survive. The recipient wants to survive the threat of a terminal illness, the seller wants to survive the threat of poverty. Ethicists continue to debate the moral content of biotechnological promises, subordinating therapeutic advantages to "higher" goals but I am forced to draw the same conclusion that I drew in 1995-that is: "Neither the diseased persons nor the genetic relations provide an answer to trading in human body parts. The live human body constitutes a vital source of supply of organs and tissues and the possibilities of its optimum utilisation should be explored. There is no scope for dogmatic postures and open mindedness should be the approach while dealing with the issue of organ transplantation. Society owes a duty to save the life of a dying man and in the event of failure to do so, it is absolutely immoral to interfere with his own arrangements by making unrealistic laws. The scarcity needs to be urgently overcome otherwise unwarranted trade and crime are liable to thrive. Commercialisation should be curbed by making the enforcement agencies efficient and not by depriving a needy person of his genuine requirements." 28

\section{REFERENCES}

1 Rohter L. Tracking the sale of a kidney on a path of poverty and hope. New York Times 2004 May 23:1.

2 The United Network for Organ Sharing (UNOS) http://www.unos.org (accessed $10 \mathrm{Jul} 2004$ ).

3 Eurotransplant Foundation http://www.transplant.org (accessed $1 \mathrm{Jul}$ 2004)

4 Siegel-Itzkovich J. Israel considers paying people for donating a kidney. BMJ 2003;326: 126-7.

5 Tuffs Heidelberg A. German surgeon under investigation over organ trading. BMJ 2003;326:568-9.

6 Harris J, Erin G. An ethically defensible market in organs. BMJ 2002;325:114-15

7 Human Transplant Act 1989 s 1 (5). London: HMSO, 1989

8 Law of 19 July 1972 of Venezuela on Organ Transplantation. International Digest of Health Legislation 1972;23:636.

9 Transplantation of Human Organs Act 1994. Gazette of India 1995 Feb 4: part II: section 3; sub-section (i).

10 American Medical Association: Council on Ethical and Judicial Affairs. Financial incentives for organ procurement: ethical aspects of future contracts for cadaveric donors. Arch Intern Med 1995; 155:581-9.

11 Marino IR, Cirillo C, Cattoi A. Market of organs is unethical under any circumstances. BMJ 2002;325:835

12 Wigmore SJ, Lumsdaine JA, Forsythe JLR. Defending the indefensible. BMJ 2002;325:835-6.

13 Moslmann F. The right to buy or sell a kidney. Lancet 2002;360:948.

14 Kahn J. Wanted: tall, smart and fertile. Bioeth Exam 1999;3:1-4 at 4.

15 Cohen CB. Selling bits and pieces of human to make babies: the gift of the Magi revisited. J Med Philos 1999;24:288-306 at 295.

16 Schmidt VH. Selection of recipients for donor organs in transplant medicine. $J$ Med Philos 1998;23:50-74 at 52.

17 Glannon W. Responsibility, alcoholism, and liver transplantation. J Med Philos $1998 ; 23: 31-49$ at 31.

18 Anon. No transplants for smokers. The Hindustan Times 2001 Feb 9:12.

19 Youngner S, Arnold RM. Philosophical debates about the definition of death: who cares? J Med Philos $2001 ; 26: 527-37$ at 527.

20 Swami P. Punjab's kidney industry. Frontline 2003 Feb 14:115-17.

21 Kidney transplant racket busted. Delhi surgeon, five donors from Andhara Pradesh among nine arrested. The Hindustan Times 2000 Dec 7:1.

22 Doctor appeals against ban on kidney sales. The Times 2000 Sept 23:11

23 Dyer O. GP struck off after offering to "fix" kidney sale. BMJ 2002;325:510.

24 Kumar S. Police uncover large scale organ trafficking in Punjab. BMJ 2003;326:180

25 Kluge E-H. Improving organ retrieval rates: various proposals and their validity. Health Care Anal 2000;8:279-95 at 283.

26 Kahn J. Dying to donate. Bioeth Exam 2003;7:1-4 at 4.

27 Radcliffe Richards J. Nefarious goings on. J Med Philos 1996;21:375-416 at 377

28 Kishore RR. Organ transplantation: consanguinity or universality? Med Law 1996;15:93-104.

29 Goyal M, Mehta RL, Lawrence JS, et al. Economic and health consequences of selling a kidney in India. JAMA 2002;288:1589-93.

30 Barnet AH, Blair RC, Kaserman DL. Improving organ donation: compensation versus markets. Inquiry 1992;29:372-8. 